\title{
ОЦЕНКА ВЛИЯНИЯ РЕЛЕВАНТНЫХ ФАКТОРОВ НА ЭФФЕКТИВНОЕ РАЗВИТИЕ ОТРАСЛИ ФИЗИЧЕСКОЙ КУЛЬТУРЫ (НА ПРИМЕРЕ ЛЕНИНГРАДСКОЙ ОБЛАСТИ)
}

\section{ASSESSMENT OF THE IMPACT OF RELEVANT FACTORS ON THE EFFECTIVE DEVELOPMENT OF THE PHYSICAL CULTURE INDUSTRY (ON THE EXAMPLE OF THE LENINGRAD REGION)}

\section{Yermilova}

Summary: The article presents the results of a study aimed at assessing the impact of relevant factors on the effective development of the physical culture industry in the Leningrad region. During the analysis of priority directions of actions carried out within the framework of the state program «Development of physical culture and sports in the Leningrad region», the current results of activities in the field of physical culture in the region were identified, allowing us to draw a conclusion about the current situation. To achieve the goal set for the study, a mathematical model was constructed for evaluating relevant factors of the physical culture and sports and economic and demographic environment using multiple regression analysis, which made it possible to explain the nature of mutual influences of the studied factors on the number of citizens who are systematically engaged in physical culture and recreation activities, in particular: increasing the capacity of infrastructure facilities in the industry increases the number of citizens, if the amount of funding is maintained, the number of specialists whose professional activities are carried out within the $\mathrm{FC}$ industry should be increased (by a maximum of $0,28 \%)$. The results of the research are of practical significance for forecasting the development of the FC industry in order to find optimal levels of factors.

Keywords: physical culture, monitoring, relevant factors, priority tasks of the industry, mathematical model, method of multiple regression analysis.

\author{
Ермилова Виктория Валерьевна \\ К.п.н., Национальный государственный университет \\ физической культуры, спорта и здоровья им. \\ П.Ф.Лесгафта, Санкт-Петербург \\ ya.vika6406@yandex.ru
}

Аннотация: В статье представлены результаты исследования, целью которого стала оценка влияния релевантных факторов на эффективное развитие отрасли физической культуры Ленинградской области. В ходе анализа приоритетных направлений действий, осуществляемых в рамках государственной программы «Развитие физической культуры и спорта в Ленинградской области», были выявлены текущие результаты деятельности в отрасли физической культуры на территории области, позволяющие сделать вывод 0 сложившейся на сегодняшний день ситуации. Для достижения поставленной перед исследованием цели было осуществлено построение математической модели оценки релевантных факторов физкультурно-спортивной и экономико-демографической среды методом множественного регрессионного анализа, посредством которого стало возможным объяснить характер взаимовлияний исследуемых факторов на количество граждан, систематически занимающихся физкультурно-оздоровительной деятельностью, в частности: увеличение пропускной способности инфраструктурных объектов отрасли ФК повышает показатель численности граждан, занимающихся физкультурно-оздоровительной деятельностью; в случае сохранения объёма финансирования следует увеличивать численность специалистов, профессиональная деятельность которых осуществляется в рамках отрасли ФК (максимум на 0,28 \%). Результаты исследования имеют практическую значимость для прогнозирования при управлении развитием отрасли ФК с целью поиска оптимальных уровней факторов.

Ключевые слова: физическая культура, мониторинг, релевантные факторы, приоритетные задачи отрасли, математическая модель, метод множественного регрессионного анализа.

\section{Введение}

$\Phi$ изическая культура (далее - ФК) как одна из отраслей экономики, выступает в качестве важного фактора социально-экономической политики региона, развитие которой способно значимо отразиться на развитии общества в целом $[4$, c.55; 6, с.19]. В ходе выработки региональной политики в отрасли ФК традиционно применяются программно-целевой и экономический методы [2, с.14]. В первом случае, регулирование деятельности в исследуемой отрасли осуществляется на основании разработки концептуальных основ политики, во-втором - на основании прогнозируемых и реальных экономических показателей эффективности в ходе выработки и реализации региональной политики [10, с.83].

В настоящее время в качестве действующих документов, регламентирующих социально-экономическую деятельность в рамках отрасли ФК Ленинградской области (далее - ЛО), выступает Постановление Правительства «Об утверждении Порядка разработки, реализации и оценки эффективности государственных программ Ленинградской области» [11] и разработанной в соответствии с названным Постановлением государственной программы «Развитие физической культуры и спорта в Ленинградской области» (далее - Программа) [5]. 
Целью настоящего исследования стала оценка влияния релевантных факторов на эффективное развитие отрасли физической культуры Ленинградской области.

\section{Теоретическое обоснование проблемы исследования}

Для достижения поставленной цели, первоначально, мы обратились к анализу ситуации, сложившейся на сегодняшний день в рассматриваемой отрасли на территории ЛО. В ходе анализа приоритетных направлений действий, осуществляемых в рамках вышеназванной Программы, были выявлены текущие результаты деятельности в отрасли ФК на территории ЛО [1, с.4-5], представленные в таблице 1.

Представленные в таблице 1 значения приоритетных показателей развития отрасли ФК, свидетельствуют об эффективности действующей государственной программы, что позволяет сделать обобщённое заключение о её положительном влиянии. Однако до сих пор остаются неразрешенные проблемы, в большей степени обусловленные недостаточностью научной обоснованности оценки влияния релевантных факторов на эффективное развитие отрасли ФК [3, с. 18; 7, с.15; 9, с.70; 14, с.88; 15, с.243; 16, с.65], что негативно отражается на её динамики.

\section{Организашия исследования}

В качестве важного этапа управления развитием отрасли ФК выступает мониторинг внешних условий, посредством которого становится возможным определить наиболее благоприятные возможности, позволяющие избежать угрозы препятствий развития исследуемой сферы деятельности. Рассмотрение отрасли с позиций системного подхода, позволяет предположить значимость влияния внешних условий на происходящие в ней изменения, как положительные, так и негативные [12, c.575].

Для разрешения основного вопроса отрасли ФК укрепление здоровья населения и формирование 3ОЖ с позиции статистического исследования, позволяющего научно обосновать факт взаимосвязи между релевантными факторами, что даст возможность путем влияния прогнозировать максимально эффективный результат [8, с.67; 13, с.34], следует найти пути разрешения двух задач: 1) приведение к количественным значениям показатели факторов; 2) устранение вариативности факторов социально-экономической среды, (доходы граждан, финансирование отрасли и т.д.)

В связи со сказанным в ходе настоящего исследования в качестве выходной переменной (функции отклика)

Результаты деятельности Правительства ЛО (по состоянию на 12.02.2020 г.)

\begin{tabular}{l|l} 
Приоритетные задачи \\
\hline 1
\end{tabular}

Сохранение и расширение инфраструктуры в отрасли ФК

Укрепление здоровья населения и формирование здорового образа жизни (далее - 30Ж)

Создание условий с целью увеличения населения, систематически занимающихся различными видами физкультурно-оздоровительной деятельностью
Результаты деятельности за период с 2017 по 2020 гг. 2

Обеспеченность спортивными сооружениями $18,23 \%$ от нормативной единовременной пропускной способности: спортивными залами - 44,84\%, плоскостными спортивными сооружениями - 17\%, плавательными бассейнами -9,1\%.

На территории функционируют 190 спортивных клубов. Завершено строительство 120 универсальных спортплощадок в сельских школах Л0, что позволяет заниматься на систематической основе около 17 тыс. детей «на селе».

Численность занимающихся физкультурно-оздоровительными видами деятельности составила 399074 человек, или 22,5\%, что превысила запланированные (21\%).

Было проведено 571 спортивных мероприятий. Обеспечена подготовка и участие спортивных команд Л0 во всероссийских и международных физкультурных мероприятиях и спортивных соревнованиях (горнолыжный спорт, плавание, настольный теннис, шашки, дзюдо. Обеспечено участие спортивных школьных команд Л0 в 13 всероссийских соревнованиях по различным видам спорта разного уровня. Проведено 2 судейских семинара, 2 тренерских семинара и 3 семинара для специалистов отрасли. На территории Л0 проведены 67 межрегиональных, всероссийских и международных спортивных соревнований.

Количество спортсменов Л0 в спортивных сборных командах России составило:

- по летним видам спорта - 103 человека;

- по зимним видам спорта - 14 человек.

Спортсмены и тренеры Л0 в количестве 109 человек получили премии Правительства Ленинградской области. Проведено 17 региональных физкультурных мероприятий. Обеспечено участие спортсменов-инвалидов Л0 в 20-ти всероссийских и международных соревнованиях и 13-ти тренировочных мероприятиях. 
нами был принят показатель численности населения, систематически занимающегося различными видами физкультурно-оздоровительной деятельностью (Y). В состав входных переменных вошли две группы факторов. В первую группу мы отнесли внешние факторы, объединяющие в себе факторы экономической и демографической среды, а именно X1 - среднедушевые доходы населения, X2 - численность населения; Х3 - численность мужчин; X4 - численность населения в дотрудоспособном возрасте. В состав второй группы - внутренние факторы, вошли факторы физкультурно-оздоровительной среды: X1 - численность штатных специалистов отрасли ФК; X2 - количество инфраструктурных сооружений; X3 финансирование отрасли. В совокупности названные факторы составили систему результативно-факторных показателей, которые были задействованы в ходе исследования в поиске оптимальных для управления отраслью ФК уровней факторов.

Построение математической модели оценки релевантных факторов осуществлялось в несколько этапов: 1 этап - выбор выходных переменных; 2 этап - установление области изменения входных факторов и их интервалов варьирования; 3 этап - определение вида математической модели; 4 этап - определение значимости коэффициентов уравнения регрессии; 5 этап - проверка адекватности модели.

В процессе исследования были выдвинуты гипотезы в соответствии с факторами:

- физкультурно-спортивной среды: X1 - с увеличением численности специалистов отрасли возрастают возможности привлечения граждан к систематическим занятиям видами физкультурно-оздоровительной деятельности; X2 - с расширение инфраструктуры отрасли увеличивается значение показателя единой пропускной способности; Х3 - увеличение финансирования отрасли создаёт более благоприятные условия для реализации физкультурно-оздоровительной деятельности;

- экономико-демографической среды: Х1 - с увеличением среднедушевых денежных доходов граждан возрастают их возможности в реализации физкультурно-оздоровительной деятельности; X2 - с увеличением численности населения увеличивается количество граждан, способных принимать активное участие в физкультурно-оздоровительной деятельности; Х3 - с увеличением численности населения в дотрудоспособном возрасте создаются наиболее благоприятные условия для роста массовости физкультурно-оздоровительного движения.

Для вычисление статистической зависимости случайной величины $\mathrm{Y}$ от нескольких других величин X1,
X2, ..> Xn, нами применен метод множественного регрессионного анализа посредством пакета прикладных программ Matlab профессора Н. Е. Проскурякова в два этапа: 1 этап включал регрессионный анализ факторов физкультурно-оздоровительной, экономической и демографической среды в отдельности; 2 этап объединял все факторы, в результате чего были получены две линейные модели (экономико-демографическая; физкультурно-оздоровительная).

\section{Результаты исследования}

Анализ первой группы факторов (социально-демографической среды) во взаимосвязи с показателем численности населения, систематически занимающимися различными видами физкультурно-оздоровительной деятельностью, показал, что количество граждан, систематически занимающихся двигательной активностью, увеличивается при росте доходов;

При сравнении факторов внутренней среды с показателем численности граждан, систематически занимающихся физкультурно-оздоровительной деятельностью, было установлено, что при увеличении финансирования и пропускной способности исследуемый показатель увеличивается более чем в 2 раза.

Апробация выстроенной модели на практике позволила произвести вычисления на примере лО и сделать следующие выводы:

1. увеличение пропускной способности инфраструктурных объектов отрасли ФК повышает показатель численности граждан, занимающихся физкультурно-оздоровительной деятельностью;

2. в случае сохранения объёма финансирования следует увеличивать численность специалистов, профессиональная деятельность которых осуществляется в рамках отрасли ФК (максимум на $0,28 \%)$.

\section{Bывод}

Резюмируя вышесказанное, на основании результатов, полученных в ходе вычислений и построения математических моделей, можно объяснить характер взаимовлиянии исследуемых факторов на количество граждан, на систематической основе занимающихся физкультурно-оздоровительной деятельностью, что в свою очередь практически значимо для прогнозирования при управлении развитием отрасли ФК с целью поиска оптимальных уровней факторов влияния. 


\section{ЛИТЕРАТУРА}

1. Архипова, С.А. Выявление и анализ факторов внешней среды, влияющих на развитие физической культуры и спорта [Текст] / С.А. Архипова // Известия Тульского государственного университета. Физическая культура. Спорт. - 2017. - № 2. - С. 3-7.

2. Бачило, Е.П. Нормативно-правовая база как фактор реформирования и развития отрасли «Физическая культура и спорт» [Текст] / Е.П. Бачило // Материалы научных трудов Всероссийской научно-практической конференции с международным участием «Стратегическое управление организациями в изменяющемся мире». - 2017. - С. 13-15.

3. Беланов, А.Э. Потребность в физической культуре как один из факторов развития личности студента [Текст] / А.Э. Беланов // Материалы Второй межрегиональной научно-методической конференции «Воспитательная среда вуза как фактор профессионального становления специалиста». - 2017. - C. $17-20$.

4. Гаджиева, М.Х.-О. и др. Кривцова М.К. «Второе поколение» показателей качества государственного управления [Текст] / М.Х.--0., Гаджиева, М.К. Кривцова // Научные записки молодых исследователей. - 2014. - С.54-56.

5. Государственная программа Ленинградской области» Развитие физической культуры и спорта в Ленинградской области» от 14 ноября 2013 года № 401 (с изменениями на 13 декабря 2019 года) [Электронный ресурс]. Режим доступа: http://docs.cntd.ru/document/537949229. (Дата обращения: 12.02.2020 г.)

6. Косова, Ю.А. Современное состояние отрасли физической культуры и спорта и пути ее реформирования [Текст] / Ю.А. Косова // Транспортное дело России - 2018. - С.19-22.

7. Кузнецова, С.Н. Факторы и условия развития физической культуры и спорта [Текст] / С.Н. Кузнецова // Young Science. - 2018. - Т. 2. - № 2. - С. 14-16.

8. Кулешов, В.К. и др. Теория управления качеством и сертификация [Текст] / В. К. Кулешов, И. С. Филатов. - Томск: Изд-во ТПУ, 2005. - С.67.

9. Курамшин, Ю.Ф. Физическая культура и спорт - важнейший фактор сохранения здоровья нации и социально-экономического развития страны [Текст] / Ю.Ф. Курамшин // Актуальные проблемы здоровья и физической культуры. - 2018. - № 1. - С. 68-73.

10. Полухина, М.Г. Социальная инфраструктура, как фактор развития физической культуры и спорта [Текст] / М.Г. Полуханова // Российский журнал сельскохозяйственных и социально-экономических наук. - 2016. - №7 (55). - С. 80-85.

11. Постановление Правительства Ленинградской области от 7 марта 2013 года №66 «0б утверждении Порядка разработки, реализации и оценки эффективности государственных программ Ленинградской области» (с изменениями на 27 декабря 2019 года). [Электронный ресурс]. Режим доступа: http:// docs.cntd.ru/document/537931984 (Дата обращения: 12.02 .2020 г.)

12. Садыкова, Ч.Р. и др. Окружающая среда как фактор развития экологии физической культуры [Текст] / Ч.Р. Садыкова, Г.Н. Хадиуллина // Материалы всероссийской научно-практической конференции с международным участием «Физическое воспитание и студенческий спорт глазами студентов».2016. - С. 575-576.

13. Степанов, А. Цели в области качества: измеримость и виды [Текст] / А. Степанов // Стандарты и качество. - 2017. - № 5 - С. 34.

14. Фёдорова, Т.Н. Специфические закономерности физического совершенствования, как факторы эффективного развития физической культуры в современном обществе [Текст] / Т.Н. Фёдорова // Международный журнал экспериментального образования. - 2019. - № 7-1. - С. 89-91.

15. Хитрова, Е.М. Принципы устойчивого развития на примере отрасли физической культуры [Текст] / Е.М. Хитрова // Baikal Research Journal - 2017. - C.243-246. 16. Цветков, В.Я. Эволюция управления качеством [Текст] / В.Я. Цветков // Образовательные ресурсы и технологии. - 2017. - №1 (18) - С.65.

(с Ермилова Виктория Валерьевна (уa.vika6406@yandex.ru). 